\title{
Regional Development, World System's Taxonomies and Inequality: A MESO-Domain Approach
}

\author{
Konstantinos Zougris, M.A., M.A., ABD. (Corresponding Author) \\ Teaching Fellow/ Dissertation Research Fellow \\ Department of Sociology \\ University of North Texas, USA \\ E-mail: konstantinoszougris@my.unt.edu
}

Richard Gee, Ph.D.

Assistant Professor of Sociology

Suomi College of Arts and Sciences

University of Finlandia

E-mail: richard.gee@finlandia.edu

\author{
Dimitrios Zaras, B.S. \\ Graduate Assistant \\ Department of Sociology \\ College of Arts and Sciences \\ University of North Texas, USA \\ Email: dimitrios.zaras@unt.edu
}

Received: December 23, 2014

Accepted: January 21, 2015 Published: May 3, 2015

doi:10.5296/ijrd.v2i1.7536

URL: http://dx.doi.org/10.5296/ijrd.v2i1.7536

\begin{abstract}
Limited research has been done about the applicability of World-Systems Theory (WST) on meso-sociological domains. This paper discusses the theoretical framework of the WST spatial divisions, applies it in subnational geographic domains, and examines the phenomenon of spatial income inequality across the Illinois' counties. We argue that the
\end{abstract}


Human Development Index (HDI) could serve as a suitable classification measure of WST regional taxonomies. Our findings indicate equivalence of structural classification between local and global geographical domains at the state of Illinois. Also our analysis on spatial inequality supports the findings of vanguard studies of the field suggesting a negative association between rurality and development, as well as an inverse relationship between rurality and income inequality at a county level.

Keywords: World-systems, Human development index, Rural-urban continuum, Regional development, Spatial inequality, Core, Semi-periphery periphery, Meso level of analysis

\section{Introduction}

Spatial income inequality is not a new field of research. Recent studies have shown that income inequality has been constantly increasing within the United States and other developed nations (Albrecht, 2007). Regardless the increasing availability of regional data since the 1970s, the spatial dimension of inequality has drawn social researchers' interest almost two decades later (Armstrong and Vickerman, 1995; Cuadrado- Roura et al., 1999; Fingleton, 1999). Until late 1980's, the dynamics of income inequality were solely approached and analyzed on international scales. Barro and Sala-I-Martin (1991) departing from the vanguard macroeconomic analysis were among the first to examine economic phenomena in meso domains. Lobao et al. (2007) argued that the motivation of studying the phenomenon of inequality -in spatial rather than socio-structural settings varies according to the conceptual framework assigned.

Former findings revealed that the regional component appears to have a significant explanatory power of income inequality (Fan and Casetti, 1994). That is, within urban and rural areas, inequality appears to be greater than between them. Henceforth, region is not only a fixed geographic entity but it also constitutes a space of dynamic structural arrangements. On the other hand Lobao and Hooks (2003) defined geographic location as an external factor to social processes constituting fixed spatial scales. Examining the determinants of inequality in standard geographic scales has an undisputed diagnostic value. It is important to examine theoretical frameworks systematically analyzing the manifest concept of spatial divides to the latent socioeconomic factors causing these spatial divisions. That is, the continuity of social and economic mechanisms would have a more intuitive value to inequality generation mechanism if approached by urban and rural settings (Lobao et.al, 2007, Champion and Hugo, 2004). In this paper we examine the phenomenon of inequality in Illinois, and simultaneously we review the framework of spatial divisions of World-Systems Theory and propose its applicability at intra-country meso domains.

The World Systems Theory (WST) is a multidisciplinary approach of structural arrangements at the global scale. It explains the world structures from a historical and social change approach. The division of labor across the world is a key factor to the spatial divisions (core, semi-periphery and periphery). The core countries are highly developed; capital intensive, technologically advanced, while the rest are either developing or underdeveloped labor intensive societies. Overall this paper serves two objectives; firstly to explore the application 
of WST taxonomies in meso regional domains (county level), and the secondly to examine the phenomenon of regional inequality across these geographic domains.

\section{Literature Review and Theoretical Foundations}

World systems' regional structures will be the backbone of this research exploring the phenomenon of the regional unequal distribution of income within the Illinois. WST is a theoretical framework of blended intellectual perspectives: the Annales' School (historical approach), Marxism (social change) and Dependency Theory (taxonomies). The theoretical implications of the world system establish an internal "war" of paradigm exposing the hermeneutics of regional differentiation in the modern capitalistic society through a macroscopic view neglecting the functionality of micro-level approaches. The division of labor, and subsequently the levels of development across regions, forms a global system of transnational and inter-regional taxonomies (core, semi-periphery and periphery).

Wallerstein (1974) explains the world system as a total, integrated social system structured with boundaries, stratification, legitimation and coherence (Wallerstein, 1974). He perceives the system as a living organism, which is self- generated and self-sustained. The evolution of its development is strictly internal. The leverage of its dynamics is integrated to the term of the world economy with the markets constituting the centripetal force of the system, whilst political institutions play a secondary role. The world structures are formed by inter-dependent regions which compete for economic prosperity (development), and political dominance. Wallerstein (1974) clarified that measuring the internal structural processes of the world system is extremely difficult task. Specifically he stated, "What characterizes a social system in my view is the fact that life within it is largely self-contained, and that the dynamics of its development are largely internal. The reader may feel that the use of the term "largely" is a case of academic weaseling. I admit I cannot quantify it." (p.229).

WST perspective supports the thesis of world of duality. It actually assumes that regional strata are based on antithetic realities; the developed and the underdeveloped, the privileged and the under-privileged, the wealthy and the poor, the oppressors and the oppressed, etc. The existence of the global regional taxonomy -based on dependence- and its inter-dependent spatial structures within the total system was extensively discussed by Hopkins and Wallerstein (1977) and Peakok and Hoover (1977) as they classified the world system to core, semi-peripheral and regional spaces. Boatca (2006) discussed the crucial institutional role of peripheries and semi-peripheries in a global social vacuum. She noted that they fall into a repetitive system of cultural, economic and political reproduction. Although, the path to modernity seems ambiguous, the objective of the core is to maintain structural functionality, while periphery always seeks for social change.

The path to modernity and economic growth (Rostow 1959) for peripheral regions is on the disposition of the core regions. In order to examine the implication of the WST, the scalar spatial relativity should be determined. The fundamental theoretical framework of WST theory assumes that the agents, geographical domains with established boundaries, interact within the holistic world system. The increasingly intertwined social structures and processes at local, regional, national and global level emerge for a shift in the deterministic focus 
(Castells, 1996). It is very extremely to quantify the internal structures forming the world system; however there are available measures to justify socioeconomic boundaries of the spatial divisions.

\subsection{World System Perspective in Meso domains}

WST has been extensively used by social researchers studying social evolution and social change (Dunn and Hall, 1993; Granoveter 1979; Lenski 1976; Nisbet 1969; Sanderson 1990). They all applied WST in different settings, yet they all seem to have reached a consensus with regards to the challenges over the selection of the unit of analysis in their studies. Focusing on individual cases (micro-level idiographic studies) could create implicative and theoretical gaps on the study of social inequality (Chase-Dunn and Hall, 1993). A general suggestion is that the theoretical and empirical inquiries of WST should involve the comparative perspective of the regional inter-societal perspective (Chase-Dunn and Hall, 1993). Also the theoretical contribution of WST could be proven instructive only in cases, in which time and space are taken under consideration.

Overcoming the austere sociological theoretical dogmas, Peter Hall (1987) pointed out the significance of examining social phenomena at meso domains. Also, Tilly (1984) asserts that the master process of social change lies on the breakeven point of structural processes of differentiation (change), and integration (institution). The process of differentiation, leads to a dichotomy between the modern advanced societies (core) and the backward traditional ones (periphery). On the other hand, integration is accomplished through hegemony, social control through legal structures, and solidarity through institutions. For instance the communities or

societies accomplishing differentiation through development establish their dominance through hegemony and consequently establish a social structure attempting to assimilate lagging regions into their own establishment.

Eric Wolf (1982), perceived the world of mankind as a "totality of interconnected processes." (p. 126). The theoretical transition from the macrosociological into the micro regional perspective via the meso domain analysis' perspective could be proven extremely complex but useful. It could explain the intermediate transitionary stages, yet it contains great danger of misleading outcomes (Tilly, 1984). Explicitly, universalizing comparisons could lead to high degree of abstractness, while individualizing comparisons could lead to biased conclusions with a very weak epistemological value. Tilly (1984) concluded that comparisons between macro-sociological and meso-level perspective could serve the purpose of finding variations in different processes and structures leading to identical expressions of causality. Lobao and Hooks (2003) argued that using counties (meso domains) as unit of analysis for studying subnational inequality increases our understanding on the role of institutions on the individual, and vice versa. That is, studying social phenomena at meso domain bridges the gap of our understanding on the interaction between individuals (micro-approach) and societies (macro-approach). In our paper we examine the structural equivalence between meso and macro domains. 


\subsection{Regional Income Inequality}

The structural rivalry among regions in meso domains is a zero sum game. One's gain is based on another region's loss consider the limited availability of resources. The world systems mechanism, as described by Wallerstein (1974), does not account for subnational structures. However, the mutual reflections between global and local structures could be approach by the glance of development and inequality. We seek for evidence on the impact of regional taxonomies (WST approach) based on regional development and on income inequality across the counties of Illinois.

Income inequality generation, as well as its consequences, covers a large portion of research of stratification (Chevan and Stokes 2000; McLaughlin, 2002). The concept of income inequality in America is a controversial issue (Glickman 2000, McLaughlin 2002). Insofar, numerous approaches and measurements have been developed in order to best diagnose and define the income differential in income inequality including; income earnings inequality (Bernard and Jensen, 1998; Bound and Johnson 1992). Also numerous researchers approached the issue from household income inequality perspective (Bishop, Formby and Smith 1997, Chevan and Stokes 2000; Levernier, Partidge and Rickman, 1998). Chevan and Stokes, (2000), Lobao et al. (1999) used spatial unit of analysis at metropolitan areas, states and counties in order to classify the levels of income inequality.

Kim (2009) conducted a research study on the institutional and regional development differential in the states of Virginia and Massachusetts. She detected a variety of methodological challenges measuring spatial income inequalities considering the unique institutional and structural characteristics of each state. McLaughlin (2002) considers a single set of relationships among the income earnings, household income at state or county level measuring inequality.

Much literature suggests that there are significant income variations among rural and urban economies (Brown and Lee 1990, McLaughlin 2002). Rural counties appear more economically homogeneous with lower levels of income inequality. Yet, McLaughlin (2002) found that household income inequality showed on average an increase on income inequality across the United States in both metropolitan and nonmetropolitan regions. In terms of spatial inequality decrease though, she found that 39 percent income inequality decline of non-metro counties and a 27 percent decline within the metropolitan counties. Finally, she concluded that economic restructuring had a higher impact on altering income inequality in nonmetropolitan regions than it had in metropolitan. In our study we expect income inequality to decrease as levels of Rurality increase.

As previously mentioned, various research projects argued that portions of inequality are predicated on the levels of economic development. Kuznets $(1953,1955)$ concluded that the dynamics, of income inequality at cross-regional level, shape an inverted $U$, meaning that the levels of income inequality would increase for newly industrialized regions, then it would reach its peak as development increases and then it would start declining at the development maturation period. However, in 1970's the U.S. experienced a rapid inequality within the country (Harrison and Bluestone 1988). They argued that the income inequality was noted 
on advanced societies due to the shift of economic structure from industrial to post industrial which is dependent on service employment sector. Therefore, we assume that the regional level of development plays a significant role on income inequality generation. Levels of development in regional analysis were used by Wallerstein (1974) in order to set up the first form of the World Systems' Theory. It will be challenging to be able to test our theory using several assumptions for measurement purposes due to the historical approach used by Wallerstein. In this paper the levels of development will be measured by the scores of Human Development Index (HDI) as proposed by Sudhid Anand and Amartya Sen (1994), and the degree of meso-domain inequality is measured by the distribution of personal income employing the gini index (1912). Finally for the levels of rurality, we rely on the ad hoc urban/rural continuum code established by the US Department of Agriculture measure (2003).

\subsection{Research Questions and Hypotheses}

Our paper proposes that World Systems Theory regional taxonomy can be applied to the subnational spatial divisions. That is, we propose a classification system based on existing measures of levels of development and levels of rurality, and we rely on the WST framework that core regions are developed and in urban settings, peripheral regions are be less developed with higher levels of rurality (agriculture based economy), while semi-peripheral counties are in between (developing and semi-rural). We expect that rural regions to be less developed than the urban ones, and that the distribution of income is more proportionate in less developed rural counties. We use an application study in Illinois, in order to support our argument. Illinois was selected as it conceptually best fit with the World Systems Theory with a single urban area and the remainder of the state being fairly rural. We divide the analytical part into two sections: The first part focuses on testing Wallerstein's thesis on World Systems' theory at the meso level, while the second examines income inequality on the system of regional classification proposed at the first part of our study.

Proposition 1: There is a systemic equivalence between global and local geographical domains expressed by the regional taxonomies subject to the levels of development.

Research Question 1: Is there any indication that Wallerstein's World Systems Theory apply to the meso level of analysis?

Hypothesis 1: Regional Development tends to be lower at rural regions than at urban regions.

Hypothesis 2: There is a statistical dependence between Regional Development Divisions and Rurality Zones.

\section{Case Study: State of Illinois}

Research Question 2: Is there any relationship between income inequality, regional development and levels of rurality across Illinois Counties?

Hypothesis 1: Income inequality is inversely related to Regional Development.

Hypothesis 2: Income inequality is inversely related to Rurality. 
Final: Dependent variable: Income Inequality

Independent Variables: Regional Development Levels of Rurality.

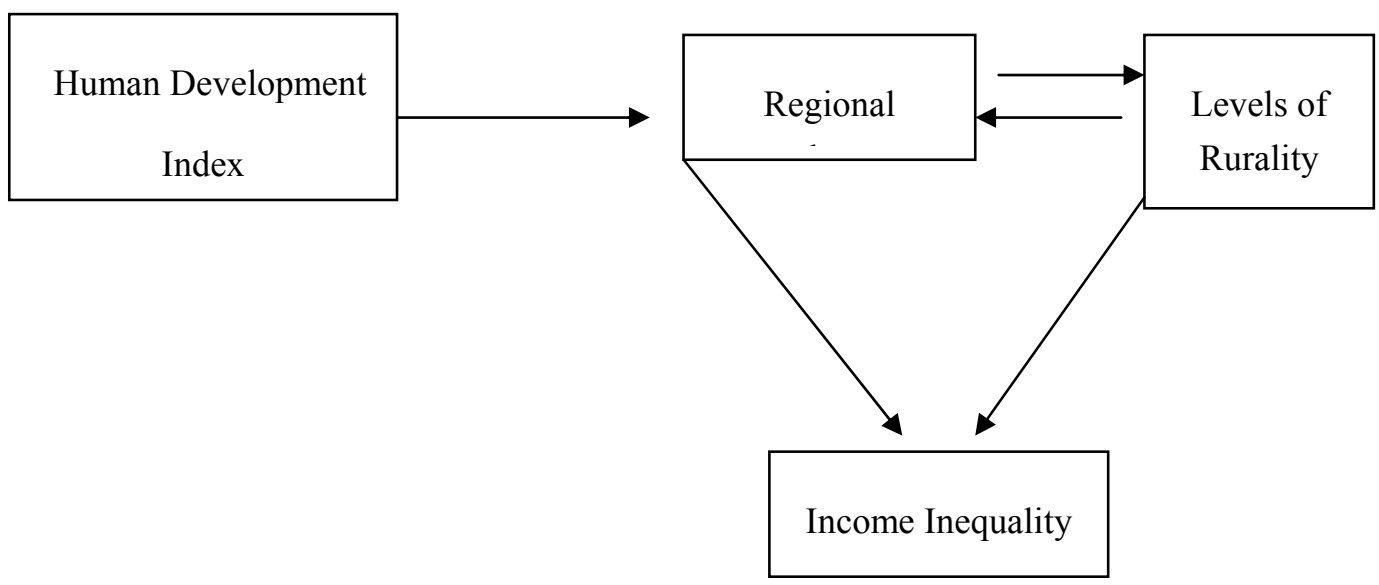

Figure 1. Schematic Presentation of the Proposed General Model

\section{Data and Measures}

We collected data from all Illinois' counties $(\mathrm{N}=102)$ for the variables included in our application study. Data of each index component (income, education and longevity) of the Human Development Index (HDI) were collected to calculate the HDI scores for each Illinois' county. Data on levels of rurality were collected by the United States Department of Agriculture (U.S.D.A.) urban/rural continuum codebook (2003). Also for the calculation of the Gini index we collected data on Illinois counties' population (U.S. Census Bureau 2003) and income per capita (Bureau of Economic Analysis. (http://www.bea.gov/newsreleases/regional/lapi/lapi_newsrelease.htm).

Following the BEA's measure, per capita personal income is calculated as the sum total of personal income of residents in a county divided by the population within the county. Population is calculated as the total number of residents within a given county. Data of educational attainment and population data were found from the U.S. Census Bureau 2003. Finally information about the longevity was found by the Center for Disease Control for the year 1999.

\subsection{Human Development Indicators}

The spatial taxonomy at the state of Illinois will be based on the human development measures of the United Nations Development Program (U.N.D.P.). We calculated each Illinois county development employing the Human Development Index (HDI) (Anad and Sen, 1994). The definition of HDI is described as,

...a summary composite index that measures a country's average achievements in three basic aspects of human development: health, knowledge, and a decent standard of living. Health is measured by life 
expectancy at birth; knowledge is measured by a combination of the adult literacy rate and the combined primary, secondary, and tertiary gross enrolment ratio; and standard of living by GDP per capita (PPP-US dollars) (http://hdr.undp.org/en/statistics/faq/question,68,en.html).

The WST spatial division within the state of Illinois is based on clustering individual HDI scores the Illinois counties. HDI scores range from 0.00 to 1.00 . A score of 0.00 indicates no development, while 1.00 designates the highest level of human development. We create the variable regional development which is based on the HDI score of each county.

Also based on the U.N.D.P. which considers regional composite scores above 0.800 (0.800 to 1.000) of high human development, scores from 0.5 to 0.799 .500 of medium human development, and scores below 0.499 (0.00 to 0.499) suggesting low human development. By combining Wallerstein's (1974) world systems structure and Anand and Sen's measure of development, we created the variable Regional Development Divisions attributed by core (HDI score $\geq 0.800)$, semi-periphery $(0.799 \geq$ HDI score $\geq 0.500)$ and periphery (HDI score $\leq$ 0.499). In mathematical notations the HDI is expressed as following,

Individual HDI Component $=\underline{\text { Actual }} \underline{x}_{1} \underline{\text { Value }- \text { Minimum }} \mathbf{x}_{1} \underline{\text { Value }}$

Maximum $\mathrm{x}_{1}-$ Minimum $\mathrm{x}_{1}$ value

Each of the indicators is given equal weight. The composite Illinois HDI is then calculated by combining and averaging the three components and can be expressed in the formula (See Appendix 1 for more information on the calculation of composite HDI scores):

Aggregate HDI $=\quad(\underline{\text { Income Index } \quad+\text { Education Index }+ \text { Longevity Index })}$

\subsection{Rurality and Rurality Zones}

We utilized the United States Department of Agriculture's (USDA) definitions of metropolitan (urban) and non-metropolitan (rural) regions. For the first part of our analysis we use the continuum codes as they appear at the USDA database to measure the variable rurality. For the second and third part of our analysis, we clustered the counties' codes creating three distinct categories of the variable rurality zones. Given that the rural-urban continuum code of 1 indicates the lowest level of rurality and that the code of 9 indicates the highest level of rurality, we divided Illinois Counties at zones (regions) and classified them as following (see Figure 2). 
Urban Counties

1. Counties in metro areas with population of $1,000,000$ residents or more.

2. Counties in metro areas with population of 250,000 to 1 million residents.

3. Counties in metro areas of fewer than 250,000 residents.

Semi-rural counties

4. Urban population of 20,000 residents or more, adjacent to a metro area.

5. Urban population of 20,000 or more, not adjacent to a metro area

6. Urban population of 2,500 to 19,999 , adjacent to a metro area

Rural Counties

7. Urban population of 2,500 to 19,999 , not adjacent to a metro area

8. Completely rural or less than 2,500 urban population, adjacent to a metro area

9. Completely rural or less than 2,500 urban population, not adjacent to a metro area.

Figure 2. Rural-Urban continuum codes

Source: 2003 Rural-Urban Continuum Codes,

http://www.ers.usda.gov/data-products/rural-urban-continuum-codes.aspx

Counties with codes 1-3 are considered urban counties, while all counties coded within the range 4-6 are semi-rural, and the ones with codes 7-9 fall in the category of rural counties.

\subsection{Income Inequality}

Measuring regional income inequality we calculate the Gini coefficient, the simplest and mostly widespread used measure (Krugman, 1991; Levernier, 1998). The Gini coefficient (1912) measures the distribution of values in a given population. In our case study we use Gini measure the per capita income in the population of 102 counties located in Illinois. The Gini coefficient value ranges between 0 and 1; whereas score of 0 indicates perfect equality (each individual has equal income with the others). On the other hand, a Gini score of 1 indicates an absolute inequality in which one individual concentrates all the total income, while the remaining people have no income at all. In short, we employ the Gini measure to detect the dispersion of income across the urban and rural counties in Illinois. In mathematical notations the Gini coefficient is expressed by:

$$
G=1-\sum_{i=0}^{N}\left(\sigma Y_{i-1}+\sigma Y_{i}\right)\left(\sigma X_{i-1}-\sigma X_{i}\right)
$$

where, $\mathrm{G}$ is the Gini coefficient, $\mathrm{N}$ is the number of residents within a county, $\mathrm{X}$ is the cumulated proportion of the population in a given area, and $\mathrm{Y}$ is cumulated proportion of personal per capita income in a given areas.

\section{Methods and Findings}

As we mentioned in the section 2.2 of this paper, Wallerstein (1974) argued that the world system is a coherent system with divisions based on economic prosperity (development) but it is extremely challenging to quantify it. . We empirically test Wallerstein's assertion at the state of Illinois using county level data on human development assuming that HDI is could serve as a proxy of regional development. Our proposition to empirically describe the internal 
structures of the meso regional system is based on the measurement of the regional development (HDI scores at county level).

The state of Illinois is constituted by a total of 102 counties. We divide Illinois' counties into three regional clusters based on their aggregate HDI. After calculating the HDI scores of each county we find that Illinois state is constituted by 25 peripheral counties, 76 semi-peripheral and only 1 core county (DuPage).

Table 1. Descriptive Statistics of HDI scores in Low, Medium and High HDI Counties in Illinois

\begin{tabular}{|c|c|c|c|c|c|c|c|}
\hline $\begin{array}{l}\text { HDI (Regi } \\
\text { Development } \\
\text { Divisions) }\end{array}$ & HDI Scores & Freq & Percent & $\begin{array}{l}\text { HDI } \\
\text { minimum }\end{array}$ & $\begin{array}{l}\text { HDI } \\
\max \end{array}$ & $\begin{array}{l}\text { HDI } \\
\text { mean }\end{array}$ & $\begin{array}{l}\text { HDI } \\
\text { standard } \\
\text { deviation }\end{array}$ \\
\hline Low (Periphery) & $0.000-0.499$ & 25 & 24.5 & 0.189 & 0.498 & 0.429 & 0.072 \\
\hline $\begin{array}{l}\text { Medium } \\
\text { (Semi-Periphery) }\end{array}$ & $0.500-0.799$ & 76 & 74.5 & 0.500 & 0.737 & 0.573 & 0.054 \\
\hline High (Core) & $0.800-1.00$ & 1 & 1.0 & 0.821 & 0.821 & 0.821 & 0.00 \\
\hline
\end{tabular}

For the peripheral counties, the average score of HDI appears to be a little greater than 0.4 with a standard deviation close to 0.070 , revealing a relevant homogeneous level of development. Approximately $75 \%$ of the counties fall into the medium range of development with an average score close to 0.6 of the HDI with a standard deviation of 0.05 . Finally, only one county (DuPage) appears to be of high regional human development (HDI=0.821). Also one county is right at the margins of the core (HDI of Cook county $=0.78$ ). Both DuPage and Cook are counties of the greater region of Chicago. Based on the development classification of the counties shows the concentration of power and resources only in one county, which is at the core of the state.

Our next step of our data organization is to classify Illinois' counties based on the USDA rural/urban continuum code measuring the levels of rurality. After merging codes 1-3, 4-6 and $7-9$, we constructed three regional categories, urban, semi-rural and rural regions. Table 2 maps the Rurality zones based on the levels of rurality across all Illinois' counties. The urban counties constitute approximately one third (35\%) of the total of 102 Illinois Counties, thirty seven percent of the fall into the semi-rural category, while almost twenty nine percent of the total of rural zones appear to be rural counties.

Table 2. Frequencies' Distribution of Urban and Semi-Rural and Rural Counties

\begin{tabular}{|c|c|c|c|c|}
\hline $\begin{array}{l}\text { Level of Rurality } \\
\text { (Rurality Zones) }\end{array}$ & $\begin{array}{c}\text { Rural } \\
\text { continuum } \\
\text { codes* }\end{array}$ & Freq & $\begin{array}{l}\text { \% Illinois } \\
\text { Counties) }\end{array}$ & Cumulative Percent \\
\hline
\end{tabular}




\begin{tabular}{llrrr}
\hline Low & 1 & 17 & 16.7 & 16.7 \\
(Urban counties) & 2 & 10 & 9.8 & 26.5 \\
& 3 & 9 & 8.8 & 35.3 \\
\hline Medium & 4 & 9 & 8.8 & 44.1 \\
(Semi-rural & 5 & 6 & 5.9 & 50.0 \\
counties) & 6 & 22 & 21.6 & 71.6 \\
\hline High & (Rural & & & \\
counties) & 7 & 20 & 19.6 & 91.2 \\
& 8 & 2 & 2.0 & 93.1 \\
& 9 & 7 & 6.9 & 100.0 \\
\hline
\end{tabular}

At a first glance, we detect that the levels of rurality in Illinois counties appear to be proportionately distributed. However the levels of human development across them appear to be more dispersed. As we see in table 3, the mean differences in HDI, between the urban, semirural and rural counties do not differ by much; for urban counties HDI mean score is 0.57 , for semirural counties is 0.54 and for the rural counties is 0.51 .Unlikely, there is a difference between the standard deviations between the different rurality zones. In urban and semirural zones seem to be similar with standard deviations of 0.086 for the urban and 0.066 for the semi-rural, but on the other hand rural counties appear to have higher dispersion of HDI (standard deviation=0.11).

After calculating the descriptive statistics on levels of rurality and development, we examine the structural associations between the global and meso domain employing the WST regional taxonomies. Based on Wallerstein's proposition that peripheral countries are more rural (agriculture economy) and less developed in comparison to core urban areas. Hence, we expect a negative relationship between levels of rurality and development. To detect the direction and the magnitude of the relationship, if any, between rurality and development, we use the raw data (numeric scores) of the rural-urban continuum codes, and the HDI scores of the entire population of Illinois Counties.

Table 3. Descriptive Statistics of Regional Development across Urban, Semi-Rural and Rural Illinois' Counties

\begin{tabular}{lcccc} 
Levels of Rurality & HDI Minimum & HDI Maximum & HDI Mean & $\begin{array}{c}\text { HDI Standard } \\
\text { Deviation }\end{array}$ \\
\hline $\begin{array}{l}\text { Urban } \\
\text { Counties } \\
\text { (N=36) }\end{array}$ & 0.398 & 0.821 & 0.57 & 0.086 \\
\hline $\begin{array}{l}\text { Semirural } \\
\text { Counties } \\
\text { (N=37) }\end{array}$ & 0.307 & 0.723 & 0.54 & 0.066 \\
\hline $\begin{array}{l}\text { Rural } \\
\text { Counties } \\
\mathbf{( N = 2 9 )}\end{array}$ & 0.189 & 0.712 & 0.51 & 0.110 \\
\hline
\end{tabular}

We employ the simple mode of correlation coefficient which detects linear dependency between two variables. Based on the correlation coefficient (Pearson's rho) rurality and regional human development have a moderate negative relationship $(\mathrm{r}=-0.301)$ (table 4$)$. That 
is, our data entail that on average as rurality increases the human development tends to decrease. Our findings support the general argument of the WST, which considers peripheral areas to be agricultural-based economies located at rural regions, while urban areas appear to be more developed and closer to the core. However, WST classifies regions by categorizing them into clusters based on certain characteristics. To establish clustering of Illinois counties, we must recode the variables Regional Development and Rurality.

Table 4. Correlation matrix of Regional Development and Rurality

\begin{tabular}{lll}
\hline & \multicolumn{1}{c}{ Regional Development (HDI) } & \multicolumn{1}{c}{ Rurality (RUCC) } \\
\hline Regional Development (HDI) & 1.000 & $-0.301^{* *}$ \\
Rurality (RUCC) & $-0.301^{* *}$ & 1.000 \\
\hline
\end{tabular}

** Significant at $\mathrm{p} \leq 0.01$.

After finding that there is a general indication of structural equivalence, at this stage of our analysis we test the hypothesis of structural equivalence between WST and regional domains focusing of regional clusters. As discusses in sections 3.1 and 3.2, we divided the counties based on their degree of rurality and development. We created a new variable Regional Development Divisions ( $R D D$ ), which is attributed by three categories, periphery (counties with $\mathrm{HDI}=0.0-0.499$ ), semi-periphery (counties with $\mathrm{HDI}=0.500-0.799$ ) and core (counties with $\mathrm{HDI}=0.800-1.00$. Also the Rurality Zones are divided in three categories, urban (codes 1-3), semirural (codes 4-6) and rural (codes 7-9). We now measure both variables at the ordinal level. Hence, we employ the Gamma measure of association (ideal for categorical variables, see appendix 1) to detect the direction as well as the magnitude of the relationship between the Regional Development Divisions and Rurality Zones. We test the hypothesis of existence of association between the two variables indicating that WST taxonomy is similar in meso regional domains.

As you can see on table 5, approximately thirty five percent of Illinois rural counties belong to periphery, while $65 \%$ of them fall within the semi-periphery, and no rural county is highly developed. As expected the vast majority (75\%) of semi-rural regions could be classified as semi-peripheral regions. Finally at the urban category of the rurality zones, only $13.9 \%$ appear be part of the periphery, $83.3 \%$ belong to semi-periphery and only one (2.8\%) falls into the core. The association between Regional Development Divisions and Rurality Zones appears to be statistically significant $(\mathrm{p}<0.05)$. There is a moderate negative relationship (gamma $=-0.361$ ) between the levels of development and the levels of rurality across regions. That is, there is an indication county in rural zones as more likely to be part of the periphery, than the semi-rural and urban ones. The results are identical to our former stage of analysis, yet our second model explores for any indication that the WST regional taxonomies (periphery, semi-periphery and core) have common characteristics with the regional (county) classification. It is very interesting that only three percent of the urban counties can be considered as core and that only thirty five percent of the rural counties belong to periphery. 
Table 5. Contingency table of regional development divisions and rurality zones

\begin{tabular}{lcccc}
\hline $\begin{array}{c}\text { Regional } \\
\text { Development } \\
\text { Divisions }\end{array}$ & Rural & Semi-Rural & Urban & Totals \\
\hline \multicolumn{1}{c}{ Periphery } & $10(34.5 \%)$ & $10(27.0 \%)$ & $5(13.9 \%)$ & $25(24.5 \%)$ \\
Semi-Periphery & $19(65.5 \%)$ & $27(73.0 \%)$ & $30(83.3 \%)$ & $76(74.5 \%)$ \\
Core & $0(0.0 \%)$ & $0(0.0 \%)$ & $1(2.8 \%)$ & $1(1.0 \%)$ \\
& & & & \\
\hline \multicolumn{1}{c}{ Totals } & $29(100 \%)$ & $37(100 \%)$ & $36(100 \%)$ & $102(100 \%)$ \\
\hline
\end{tabular}

The final step of our analysis investigates the phenomenon of income inequality from a regional development and regional rurality perspective. In our model of regional income inequality we consider the regional levels of human development and the regional levels of rurality as the two factors affecting inequality. We detected that there is a highly variability of personal per capita income within core counties and a moderate one in the semi-periphery and periphery. Table 6 shows that in peripheral counties the per capita income is close to 25,000 dollars, while in the medium development regions (semi-periphery) it is about 30,000 dollars and in the core county of Illinois the personal income is approximately 50,000 dollars in 2004, revealing high inequality between the core, periphery and semi-periphery. Employing the Gini coefficient we detect that income inequality within core counties is greater $($ Gini coefficient $=0.550)$ than semi-peripheral counties (Gini coefficient $=0.421$ ), and a lot greater than peripheral ones (Gini coefficient $=0.388$ ).

Table 6. Descriptive Statistics of Income Inequality across Regional Development Divisions

\begin{tabular}{|c|c|c|c|c|c|c|}
\hline $\begin{array}{l}\text { Regional } \\
\text { Development } \\
\text { Divisions }\end{array}$ & $\begin{array}{l}\text { Personal } \\
\text { Capita } \\
\text { mean }\end{array}$ & $\begin{array}{r}\text { Per } \\
\text { Income }\end{array}$ & Population & $\begin{array}{l}\text { Gini } \\
\text { mean }\end{array}$ & coefficient & HDI mean \\
\hline Semi-periphery & $29,539.88$ & & $10,988,252$ & 0.421 & & 0.573 \\
\hline Core & 48,115 & & 920,457 & 0.550 & & 0.821 \\
\hline
\end{tabular}

With regards to the relationship between rurality and income inequality, urban counties appear to have high overall levels of personal per capita income, but also they have the highest degree of degree of inequality in Illinois (Gini coefficient= 0.458). The lowest degree of inequality appears in rural counties, so as the lowest income.

Table 7. Descriptive statistics of income inequality across Rurality Zones

\begin{tabular}{lcccccc}
\hline $\begin{array}{l}\text { Rurality } \\
\text { zones }\end{array}$ & $\begin{array}{l}\text { Rural } \\
\text { continuum } \\
\text { codes }\end{array}$ & $\begin{array}{l}\text { Frequency } \\
\text { Distribution }\end{array}$ & $\begin{array}{l}\% \\
\text { Illinois } \\
\text { Counties }\end{array}$ & $\begin{array}{l}\text { of } \\
\text { Personal per } \\
\text { capita income } \\
\text { mean }\end{array}$ & $\begin{array}{l}\text { Gini } \\
\text { Coefficient } \\
\text { mean }\end{array}$ & $\begin{array}{l}\text { Gini } \\
\text { Standard } \\
\text { Deviation }\end{array}$ \\
\hline Urban & 1 & 17 & 16.7 & 32,105 & 0.458 & 0.057 \\
& 2 & 10 & 9.8 & 30,502 & 0.439 & 0.035 \\
& 3 & 9 & 8.8 & 28.936 & 0.424 & 0.042 \\
\hline Semi-Rural & 4 & 9 & 8.8 & 31,185 & 0.410 & 0.023 \\
& 5 & 6 & 5.9 & 27,525 & 0.346 & 0.024 \\
& 6 & 22 & 21.6 & 27,813 & 0.404 & 0.029 \\
\hline Rural & 7 & 20 & 19.6 & 25,847 & 0.395 & 0.031 \\
& 8 & 2 & 2.0 & 27,846 & 0.420 & 0.113 \\
& 9 & 7 & 6.9 & 25,310 & 0.400 & 0.023 \\
\hline
\end{tabular}


With our model we test for linear dependence between income inequalities (dependent variable) with the regional development (independent variable) and the rurality (independent variable). As we can see table 8 , there is statistically significant $(\mathrm{p}<0.05)$ moderate positive relationship (Pearson's rho $=0.323$ ) between the income inequality and regional development. Also our based on our analysis, we find that there is a significant $(p<0.05)$ moderate negative relationship between income inequality and rurality. From the results, table 8 , it also appears that there is a negative correlation between income inequality and levels of development. So as the regional development increase, the level of inequality decreases.

Table 8. Multi-Correlation Matrix between Income Inequality, Regional Development and Rurality

\begin{tabular}{lllll}
\hline & $\begin{array}{l}\text { Income } \\
\text { (Gini Coefficient) }\end{array}$ & $\begin{array}{l}\text { Inequality } \\
\text { Regional } \\
\text { (HDI) }\end{array}$ & Development & Rurality (RUCC) \\
\hline $\begin{array}{l}\text { Income Inequality } \\
\text { (Gini Coefficient) }\end{array}$ & 1 & $0.323^{* *}$ & $-0.440^{* *}$ \\
$\begin{array}{l}\text { Regional } \\
\begin{array}{l}\text { Development (HDI) } \\
\text { Rurality (RUCC) }\end{array}\end{array}$ & $0.323^{* *}$ & 1 & $-0.301^{* *}$ \\
\hline
\end{tabular}

**significant at the 0.01 level (2-tailed).

Our results indicate that regional income inequality tends to increase as the level of rurality decreases, which support McLaughlin's (2002) predictions. Also based on our findings we anticipate higher capital accumulation at core counties, which is prominent to WST assertions. Also the income inequality tends to be higher at the core, while a more equally distributed income occurs at peripheral regions. Expanding our discussion to economic growth literature our findings indicate that there is empirical evidence supporting Kuznets (1955) hypothesis stating that dynamically income inequality forms an inverted $U$ shape distribution. That is, the levels of income inequality would increase for newly developed regions, and it would reach its peak as development increases followed by a declining pattern at later stages. DuPage County is not a newly developed region; hence it is remarkable that high inequality still remains intact. Considering that most of rural Illinois' counties are farming dependent economies, there is an indication that they are at the first stage of inverted $U$ shape inequality as proposed by Kuznets. One explanation could be that low inequality in rural areas occurs during the transition period, while at industrial and postindustrial societies the levels of inequality tend to increase. On the other hand in urban areas the shift from the industrial to postindustrial era might be the case of increasing inequalities as well. Finally, our findings show promise for future research testing Harrison and Bluestone (1988) argument that income inequality on advanced regions occur due to the transition from industrial (manufacturing) to post-industrial (service) based economy. Therefore further research needs to be performed to explore the regional industrial and post-industrial economic structure of Illinois and investigate its association to income inequalities. 


\section{Conclusions and Future Research}

With this paper we tried to explore the applicability of World Systems' regional taxonomies and we explored the phenomenon of income inequalities at a county level. Since our study is exploratory, our analysis focused only within the geographic boundaries of Illinois. Most studies employing WST were based solely on global level of analysis. We proposed that part of World' Systems Theory structural framework may be applicable on meso structural domains. Considering the assumptions we discussed, and recognizing various limitations of our model, we found some premise on our proposition of structural equivalence between macro and meso scales. Wallerstein argued that the division of the world countries is constituted by interdependent components of an integrated functional (occupational) system. Following his rationale we explained the spatial structure of the state of Illinois as an integrated system formed by counties (functional divisions), and we explored their taxonomy based on the levels of development. We calculated the Human Development Index (HDI) in order to regionally divide state of Illinois into three distinct regional clusters based on their level of development. We found that the vast majority of both urban and rural counties fall into the category of semi-periphery (medium levels of development), which creates ambiguity in WST structures on meso domains. However, our analysis revealed that higher levels of rurality signify lower levels of development, which along with WST affirmation, verifies vanguard sociological research studies on regional development.

In conclusion, we found that less developed (peripheral) counties appear to have lower levels of capital accumulation than the high developed counties (core), yet personal incomes in peripheral counties appear proportionately distributed. That is, our analysis revealed a moderate negative relationship between the income inequality and levels of rurality at the state of Illinois. Rural counties tend to more homogeneous with lower level of per capital income than the urban areas. Recognizing the methodological and theoretical ambiguity over the applicability of WST in regional level, we conclude that in the state of Illinois there is an indication of structural equivalence between the meso and macro structures. Our findings of the model testing for association between regional inequality, regional development and levels of rurality, reproduce former findings of vanguard studies in spatial inequality in the U.S., where rural regions appear to be less developed with lower levels of personal income inequality in comparison to urban areas where the average personal income is at a higher level, yet it is disproportionately distributed. Future research shall be conducted to explore the structural equivalence between macro and meso level of analysis focusing on the occupational divides between the rural and urban areas. Also further research needs to be conducted to examine the ambiguity of semi-peripheral regions that appear to be constituted by a mix of rural, semi-rural and urban counties. Finally, future research shall address the dependency between the rural and urban regions and detect the dimensions of factor endowments differential, the variations on entrepreneurial activities, and the unequal human capital accumulation in urban and rural regions. 


\section{References}

Albrecht, D. E., \& Albrecht, S. G. (2007). The benefits and costs of inequality for the advantaged and disadvantaged. Social Science Quarterly, 88(2), 382-403. http://dx.doi.org/10.1111/j.1540-6237.2007.00463.x

Anand, S., \& Sen, A. K. (1994). Human development index: Methodology and measurement. New York: Oxford Press. http://hdr.undp.org/sites/default/files/oc12.pdf

Armstrong, H. W., \& Vickerman, R. W. (1995). Convergence and divergence among European regions. London: Pion.

Barro, R., \& Sala-I-Martin, X. (1991). Convergence across states and regions. Brookings papers on Economic Activity, 1, 107-182. http://dx.doi.org/10.2307/2534639

Bernard, A. B., \& Jensen B. J. (1998). Understanding increasing and decreasing wage inequality. Cambridge, MA: National Bureau of Economic Research. http://dx.doi.org/10.3386/w6571

Bishop, J. A., Formby, J. P., \& Smith, J. W. (1997). Demographic change and income inequality in the United States, 1976-1989. Southern Economic Journal, 64, 34-44. http://dx.doi.org/10.2307/1061035

Boatca, M. (2006). Semi-peripheries in the world-system: Reflecting eastern European and Latin American experiences. Journal of World Systems Research, 12(2), 321-346.

Brown, D. I., \& Lee, M. A. (1999). Persisting inequality between metropolitan and nonmetropolitan America: Implications for theory and policy. In P. Moen, D. Dempster-McClain, \& H. A. Walker (Eds.), A nation divided: Diversity, inequality and community in American society (pp. 151-167). Ithaca: Cornell University Press.

Bureau of Economic Analysis. (2008). Local area personal income definitions.

Champion, T., \& Hugo, G. (2004). New forms of urbanization: beyond the urban-rural dichotomy. Virginia: Ashgate Publishing Company.

Chase-Dunn, C., \& Grimes, P. (1995). World-Systems analysis. Annual Review of Sociology 21, 387-417. http://dx.doi.org/10.1146/annurev.so.21.080195.002131

Chase-Dunn, C., \& Hall, T. D. (1993). Comparing world-systems: Concepts and working hypotheses. Social Forces, 71(4), 851-886. http://dx.doi.org/10.1093/sf/71.4.851

Chevan, A., \& Stokes, R. (2000). Growth in family income inequality, 1970-1990: Industrial restructuring and demographic change. Demography, 37, 365-380. http://dx.doi.org/10.2307/2648048

Cuadrado-Roura, J., Begona Garcia-Greciano, B., \& Raymond, J. (1999). Regional convergence in productivity and productivity structure: The Spanish case. International Regional Science Review, 22, 35-53. http://dx.doi.org/10.1177/016001799761012190 
Fan, C. C., \& Casetti E. (1994). The spatial and temporal dynamics of U.S. regional income inequality, 1950-1989. The Annals of Regional Science, 28, 177-196.

Fingleton, B. (1999). Estimates of time to economic convergence: An analysis of regions of the European Union. International Regional Science Review, 22, 5-35. http://dx.doi.org/10.1177/016001799761012181

Gini, C. (1912). Variability and Mutability. Bologna: Cuppini.

Glickman, N.J. (2000). Prosperity and inequality among America's cities and regions. In R. Marshall (Ed.), Back to Shared Prosperity (pp. 395-406). Armonk, NY: M.E.Sharpe Inc.

Granovetter, M. (1979). The idea of advancement in theories of social evolution and development. American Journal of Sociology, 85, 489-515. http://dx.doi.org/10.1086/227047

Hall, P. (1987). Interactionism and the study of social organization. Sociological Quarterly. 28, 1-22. http://dx.doi.org/10.1111/j.1533-8525.1987.tb00280.x

Hopkins, T. K., Wallerstein I. (1977). Patterns of development of the modern world system. American Sociological Review, 1, 111-145.

Kim. S. (2009). Institutions and US regional development: a study of Massachusetts and Virginia. Journal of Institutional Economics, 5(2), 181-205.

Krugman, P. (1991a). Geography and trade. Cambridge: MIT Press.

Kuznets, S. (1953). Shares of upper income groups in income and savings. New York: National Bureau of Economic Research.

Kuznets, S. (1955). Economic growth and economic inequality. American Economic Review 45(1).1-28.

Lenski, G. (1976). History and social change. American Journal of Sociology. 82. 548-564. http://dx.doi.org/10.1086/226353

Levernier, W., Partridge M. D., Rickman, D. S. (1998). Differences in metropolitan and nonmetropolitan U.S. family income inequality: A cross-county comparison. International Regional Science Review 18.355-78.

Lichter, D. T., Johnson, K. (2007). The changing spatial concentration of America's rural $\begin{array}{lllll}\text { poor } & \text { population. } & \text { Rural } & \text { Sociology. } & 72:\end{array}$ http://dx.doi.org/10.1526/003601107781799290

Lobao, L, Rulli J., Brown, L. A. (1999). Macrolevel theory and local-level inequality: Industrial structure, institutional arrangements, and the political economy of redistribution, 1970 to 1990. Annals of the Association of American Geographers 89.571-601. http://dx.doi.org/10.1111/0004-5608.00163

Lobao, L. (1990). Locality and inequality: Farm structure, industry structure, and socioeconomic conditions. Albany: The State University of New York Press. 
Lobao, L., Hooks, G., \& Tickamyer, A. (2007). The sociology of spatial inequality. Albany: The State University of New York Press.

Lobao, L., \& Hooks, G. (2003). A Public Employment, Social welfare and local well-being: Does a lean and mean government benefit the masses. Social Forces 81. 519-556. http://dx.doi.org/10.1353/sof.2004.0016

McLaughlin, D. (2002). Changing income inequality in nonmetropolitan counties, 1980 to $\begin{array}{llll}1990 . & \text { Rural } & \text { Sociology. } & 67(4) .\end{array}$ http://dx.doi.org/10.1111/j.1549-0831.2002.tb00117.x

Nisbet, R. (1969). Social change and history: Aspects of the western theory of development. London and New York: Oxford University Press.

Peacock W., Hoover, G. A., \& Killian, C. D. (1988). Divergence and convergence in international development: A decomposition analysis of inequality in the world system. American Sociological Review, 53, 838-852. http://dx.doi.org/10.2307/2095894

Rostow. W. W. (1959). The stages of economic growth. The Economic History Review, 12, 1-16. http://dx.doi.org/10.1111/j.1468-0289.1959.tb01829.x

Tilly, C. (1984). Big structures; Large processes; Huge comparisons. New York, NY: Russell Sage Foundation.

U.S. Census Bureau. (2004). Population pyramids and demographic summary indicators. Retrieved from http://www.census.gov/ipc/www/usinterimproj/

United Nations Development Report. (2005). Human development indices.

United Nations Development Report. (2005). Statistics of the human development report.

United Nations Development Report. (2005). The human development concept.

United States' Department of Agriculture; Economic Research Service. (2003). Measuring rurality: Rural-urban continuum codes.

Wallerstein, I. (1974). The modern world system: Capitalist agriculture and the origins of the European world-economy in the $16^{\text {th }}$ Century. New York, NY: Academic Press.

Wolf, E. R. (1982). Europe and the people without History. Berkley, CA: University of California Press.

\section{Appendix 1}

HDI (Human Development Index) HDI aggregate score:

Individual HDI Component $=\underline{\text { Actual }} \underline{x}_{1} \underline{\text { Value }- \text { Minimum } x_{1}} \underline{\text { Value }}$

Maximum $\mathrm{x}_{1}-$ Minimum $\mathrm{x}_{1}$ value

Aggregate HDI $=\quad(\underline{\text { Income Index }}+$ Education Index + Mortality Index $)$ 


\section{Macrothink}

International Journal of Regional Development

ISSN 2373-9851 2015, Vol. 2, No. 1

Income Index $=\quad(\underline{\text { Per Capita Income }+ \text { Gini Coefficient }+ \text { Poverty Rate })}$

3

Education Index $=\quad \underline{\text { (Highschool Attainment }+ \text { Bachelors }+ \text { Professional Degrees })}$

3

Mortality Index $=\quad$ (Adjusted Mortality Rate + Infant Mortality Rate)

2

Pearson rho

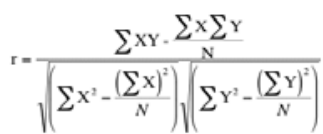

\section{Gamma correlation}

$G=\frac{N_{a}-N_{i}}{N_{a}+N_{i}}$

\section{Copyright Disclaimer}

Copyright for this article is retained by the author(s), with first publication rights granted to the journal.

This is an open-access article distributed under the terms and conditions of the Creative Commons Attribution license (http://creativecommons.org/licenses/by/3.0/). 